\title{
Correction to: Tram system related cycling injuries
}

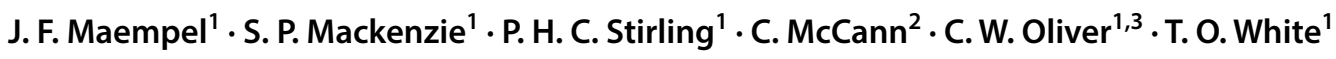

Published online: 21 February 2018

c) Springer-Verlag GmbH Germany, part of Springer Nature 2018

\section{Correction to: Archives of Orthopaedic and Trauma Surgery https://doi.org/10.1007/s00402-018-2890-4}

The author would like to correct the errors in the publication of the original article. The corrected details are given below for your reading.

In the Methods section, first paragraph should read as:

A retrospective review of trust-wide electronic patient records was undertaken and all patients presenting to NHS Lothian emergency services across three hospital sites covering the city of Edinburgh and surrounding suburbs as well as Livingston, with injuries related to the tram system between May 2009 and April 2016 were identified. All patient records for acute services at our trust are electronic. Two hundred and fifty-one patients who suffered injuries in relation to the tram system during this time period were identified. Of these, 191 suffered such injuries while riding a bicycle and form the cohort under review in this study.

The original article has been corrected.
The original article can be found online at https://doi.org/10.1007/ s00402-018-2890-4.

\section{J. F. Maempel}

julian.maempel@nhs.net

1 Department of Trauma and Orthopaedics, Royal Infirmary of Edinburgh, 51, Little France Crescent, Edinburgh EH16 4SA, UK

2 Edinburgh Medical School, College of Medicine and Veterinary Medicine, Univeristy of Edinburgh, Edinburgh, UK

3 Physical Activity for Health Research Centre, University of Edinburgh, Edinburgh, UK 